\title{
Activation of Quinolines by Cationic Chalcogen Bond Donors
}

\author{
P. Wonner $\$$ \\ T. Steinke \\ S. M. Huber* (1)
}

Fakultät für Chemie und Biochemie, Ruhr-Universität Bochum, Universitätsstraße 150, 44801 Bochum, Germany stefan.m.huber@rub.de

$\S$ Both authors contributed equally

Published as part of the Cluster Organosulfur and Organoselenium Compounds in Catalysis

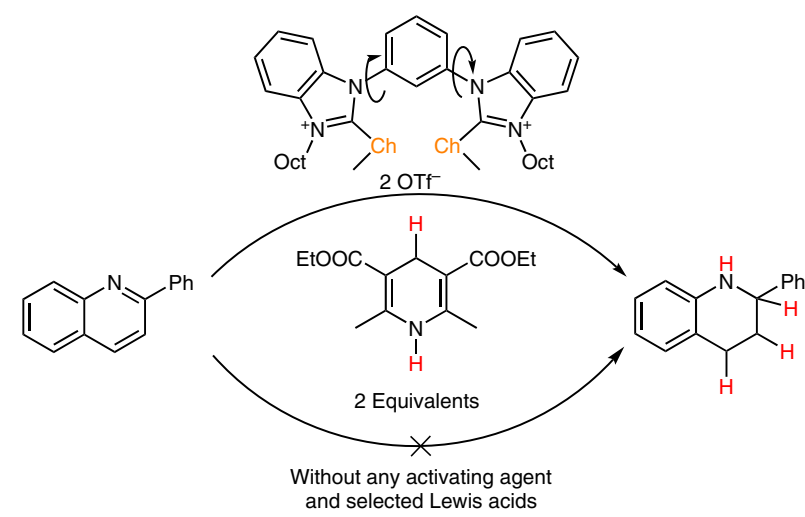

ity may be fine-tuned by variation of both substituents $\mathrm{R}$ and $\mathrm{R}^{\prime}$ (Figure 1 ). In solid-state chemistry and crystal engineering, chalcogen bonding has increasingly been utilized in the last 20 years or so. ${ }^{11,15,16}$ As an intramolecular interaction, it has also been used in organic synthesis since the pioneering works of Tomoda $^{17}$ and Wirth. ${ }^{18}$ Pioneering studies on intermolecular interactions in solution were recently published by Taylor ${ }^{19,20}$ and Beer $^{21-23}$ in anion-recognition processes, and in 2017 the group of Matile ${ }^{24,25}$ and our group ${ }^{26,27}$ reported the first applications of intermolecular chalcogen bonding in organocatalysis: quinoline derivatives were activated by neutral $\mathrm{ChB}$ donors, while cationic $\mathrm{ChB}$ donors were used in halide abstraction reactions. Two further reactions of the latter type were reported subsequently. 28,29

However, the application of cationic $\mathrm{ChB}$ catalysts in the activation of neutral compounds is still unexplored, even though a significantly stronger activation should be expected compared with neutral catalysts. This is particularly true since in these reactions - in contrast to halide abstractions - no interfering anion (leaving from the substrate) is present.

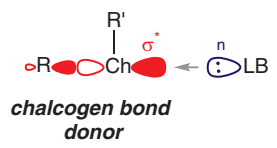

Figure 1 Chalcogen bonding as $n \rightarrow \sigma^{*}$ type interaction between a Lewis base (LB) and a chalcogen bond donor $(\mathrm{Ch}=\mathrm{S}$, Se, Te)

As a simple benchmark reaction, the reduction of quinoline derivatives (Scheme 1) was chosen for several reasons: (a) most importantly, a series of reports is available with data on the performance of halogen or (neutral) chalcogen bonding organocatalysts; ${ }^{24,25,30}$ (b) the reaction can be easily monitored via ${ }^{1} \mathrm{H}$ NMR spectroscopy; (c) a large number of quinoline derivatives can be employed; and (d) no back- 
ground reactivity is observed at room temperature in the absence of activating agent (Table 1 , entry 1 ). It should be noted that, at the same time, the reaction is not without its issues, particularly with regard to halogen bonding, as the action of hidden acid traces such as HI cannot easily be ruled out. ${ }^{31,32}$ This is less relevant for chalcogen bonding, though, as the generation of acid seems much less likely.

As cationic ChB donors, sulfur- and selenium-based imidazolium and benzimidazolium derivatives were chosen, with the selenium compounds already having been applied in halide abstraction reactions. ${ }^{26,27}$<smiles>[R]c1ccc2nc([Tl])ccc2c1</smiles>

1a-d

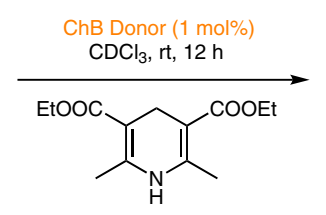

2

$$
\text { a: } \mathrm{R}^{1}=\mathrm{Ph} \text { and } \mathrm{R}^{2}=\mathrm{H}
$$$$
\text { c: } \mathrm{R}^{1}=\mathrm{H} \text { and } \mathrm{R}^{2}=\mathrm{NO}_{2}
$$

$$
\text { b: } R^{1}=M e \text { and } R^{2}=F
$$$$
\text { d: } \mathrm{R}^{1}=\mathrm{H} \text { and } \mathrm{R}^{2}=\mathrm{OMe}
$$

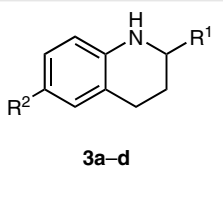

Scheme 1 Reduction of different quinoline derivatives $\mathbf{1 a}-\mathbf{d}$ with Hantzsch ester 2 (2.4 equiv) in the presence of sulfur- and seleniumbased cationic chalcogen bond donors

The preparation of all $\mathrm{ChB}$ donors investigated herein followed the same synthetic route, which is given in Scheme 2 (yields for each step and more details are provided in the Supporting Information). The first step involves the alkylation of the bis-heterocyclic compound, followed by introduction of the chalcogen under basic conditions and a second alkylation of the resulting chalcogenourea to yield the final catalysts as triflate salts. ${ }^{26}$

The tested ChB donors and reference compounds are shown in Figure 2. Each contains a characteristic cationic bis(benz)imidazolium scaffold as well as octylated side chains for improved solubility. Some of the compounds feature a trifluoromethyl group on the central benzene core.
Table 1 Performance of Reference Compounds (Figure 2) in the Re-

\begin{tabular}{|c|c|c|c|}
\hline Entry & Catalyst & $\mathrm{mol} \%^{\mathrm{a}}$ & Yield of $3 a(\%)^{b}$ \\
\hline 1 & - & - & $<5$ \\
\hline 2 & $8^{\mathrm{H}}$ & 1 & 64 \\
\hline 3 & $9^{\mathrm{H}}$ & 1 & 53 \\
\hline 4 & syn/anti-10 $0^{\mathrm{H} \mathrm{C}}$ & 1 & 18 \\
\hline 5 & anti-10 $0^{\mathrm{Cl}}$ & 1 & $<5$ \\
\hline 6 & syn-10' & 1 & 88 \\
\hline 7 & $11^{\mathrm{s}}$ & 1 & $<5$ \\
\hline 8 & $11^{\mathrm{se}}$ & 1 & $<5$ \\
\hline 9 & $12^{\mathrm{s}}$ & 1 & $<5$ \\
\hline 10 & $12^{\mathrm{Se}}$ & 1 & $<5$ \\
\hline 11 & $\operatorname{syn}-13^{s}$ & 1 & $<5$ \\
\hline 12 & anti-13 $3^{\mathrm{S}}$ & 1 & $<5$ \\
\hline 13 & anti-13 $3^{\text {se }}$ & 1 & $<5$ \\
\hline
\end{tabular}
duction of 2-Phenylquinoline (1a)

a Catalyst loading with respect to the amount of $\mathbf{1 a}$.

${ }^{b}$ After $12 \mathrm{~h}$ reaction time. Determined via ${ }^{1} \mathrm{H}$ NMR spectroscopy and relative to TES as internal standard. Averaged values of three measurements. A measurement / analysis error of $\pm 10 \%$ is assumed.

c Inseparable 40:60 mixture of syn-10 ${ }^{\mathrm{H}}$ and anti-10 ${ }^{\mathrm{H}}$.

This serves two purposes: it allows easy tracking of potential catalyst decomposition via ${ }^{19} \mathrm{~F}$ NMR spectroscopy and it allows the separation of syn- and anti-isomers. Based on the well-known supramolecular concept of preorganization, the former is expected to be more active than analogous compounds with freely rotating chalcogen bonding moieties (such as $\mathbf{8}$ or $\mathbf{9}$ ).

First orientating experiments were performed with our previously most active ChB catalyst ${ }^{26,27}$ syn-10 10Me $^{\text {SeM }}$ and phenylquinoline (1a) as substrate to find an optimal reaction profile regarding reaction time, catalyst loading, and overall concentration (in view of solubility issues of com-<smiles>FC(F)(F)c1c(-n2cnc3ccccc32)cccc1-n1cnc2c(C(F)(F)F)cccc21</smiles>

4

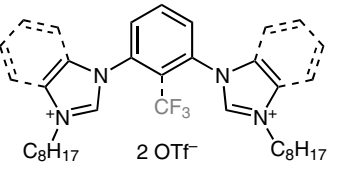

ii)

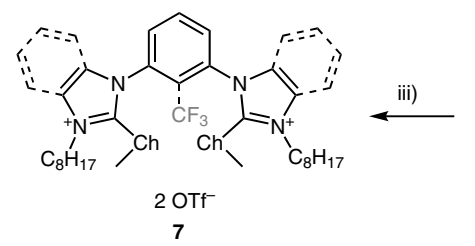

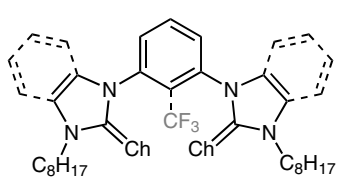

6

Scheme 2 Schematic syntheses of different sulfur- and selenium-based chalcogen bond donors. (i) $\mathrm{C}_{8} \mathrm{H}_{17} \mathrm{OTf}\left(2.5\right.$ equiv), anhyd. $\mathrm{CH}_{2} \mathrm{Cl}_{2}(0.1 \mathrm{M})$, r.t., $24 \mathrm{~h}$; (ii) $\mathrm{Ch}$ (2.5 equiv), $\mathrm{Cs}_{2} \mathrm{CO}_{3}$ (2.5 equiv), anhyd. $\mathrm{MeOH}$ (0.1 M), reflux, 24 h; (iii) MeOTf (2.5 equiv), anhyd. $\mathrm{CH}_{2} \mathrm{Cl}_{2}(0.1 \mathrm{M})$, r.t., 24 h; $\mathrm{Ch}=\mathrm{S}, \mathrm{Se}$. 


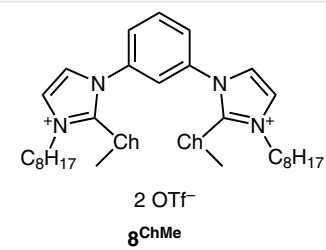

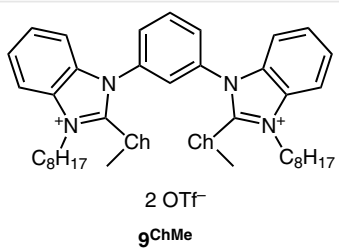

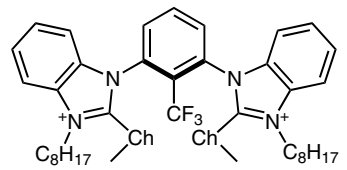
$2 \mathrm{OTf}^{-}$ syn-10 ${ }^{\mathrm{ChMe}}$

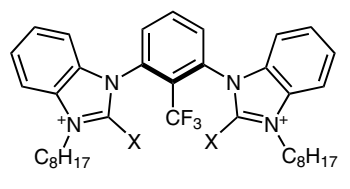
$2 \mathrm{OTf}^{-}$ syn-10 ${ }^{\mathrm{X}}$

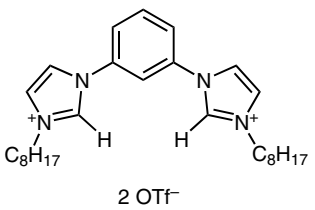
$8^{H}$<smiles>CCCCCCn1ccn(-c2cccc(-n3ccn(C4CCCCC4)c3=O)c2)c1=O</smiles>
$11^{\mathrm{ch}}$<smiles>CCCn1c(=O)n(-c2cccc(-n3c(=O)n(CC)c4ccccc43)c2C)c2ccccc21</smiles>

syn-13 ${ }^{\mathrm{ch}}$

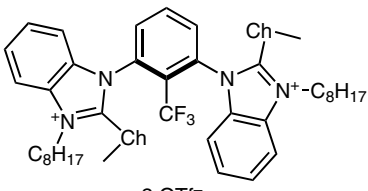

$2 \mathrm{OTf}^{-}$ anti-10 $0^{\mathrm{ChMe}}$<smiles>[X]c1c(-n2c([X])[n+](CC)c3ccccc32)cccc1-n1c([X])[n+](CCCCC)c2ccccc21</smiles>

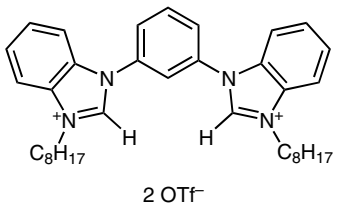
$9^{\mathrm{H}}$<smiles>CCCn1c(=O)n(-c2cccc(-n3c(=O)n(C4CCCCC4)c4ccccc43)c2)c2ccccc21</smiles>
$12^{\mathrm{ch}}$

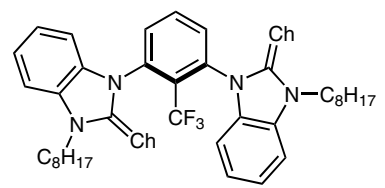

anti-13 ${ }^{\mathrm{ch}}$
Figure 2 Overview of the tested chalcogen bond donors and reference compounds; Ch = S, Se (except syn-13); X = H, I, Cl (only anti-10).

pound 2 ). In the presence of $1 \mathrm{~mol} \%$ of catalyst syn-10 ${ }^{\text {SeMe }}$, full conversion of the reaction in $\mathrm{CDCl}_{3}(0.042 \mathrm{~mm})$ was observed after 12 h. ${ }^{33}$ Accompanying ${ }^{19} \mathrm{~F}$ NMR measurements (see the Supporting Information) confirmed the stability of the catalyst under these reaction conditions. This was also corroborated by a second run, in which further starting material 1a was added to a fully converted reaction mixture, giving a virtually identical yield of product 3a and thus ruling out the action of accumulated decomposition products.

With this promising lead result in hand, various reference compounds (Figure 2) were investigated to dismiss an activation that is not based on chalcogen bonding. Surpris- ingly, however, the non-selenated compounds syn/anti-10 ${ }^{\mathbf{H}}$, $\mathbf{8}^{\mathbf{H}}$ and $\mathbf{9}^{\mathbf{H}}$ were also active (Table 1 , entries 2-4). For instance, the most active reference compound $\mathbf{8}^{\mathbf{H}}$ gave $64 \%$ yield of compound $\mathbf{3 a}$ after $12 \mathrm{~h}$ reaction time. To exclude the possibility that the observed activation is solely driven by cation- $\pi$ interactions or hydrogen bonds via the backbone protons, the chlorinated reference compound anti$\mathbf{1 0}^{\mathrm{Cl}}$ was tested. ${ }^{34}$ As previous work had shown that its chlorine substituents do not form halogen bonds, ${ }^{35,36}$ its potential modes of action (cation- $\pi$ and hydrogen bonding) would be shared by the core structure of syn-10 $\mathbf{1 0}^{\text {SeMe }}$. The chlorinated compound showed no activity (Figure 3; Table 1 , entry 5 ), which strongly indicates that the activity of syn$\mathbf{1 0}^{\text {SeMe }}$ can indeed be ascribed to chalcogen bonding. As a further consequence, the performance of compounds syn/anti-10 $\mathbf{H}^{\mathbf{H}}, \mathbf{8}^{\mathbf{H}}$ and $9^{\mathbf{H}}$ is likely based on hydrogen bonding. To verify these results, reference compound syn-10 $\mathbf{I}$ and urea derivatives 11-13 (Figure 2 and Scheme 2) were also employed as catalyst candidates. The iodinated compound syn-10 $\mathbf{1 0}^{\mathrm{I}}$ provided $88 \%$ yield of $3 \mathrm{a}$ after $12 \mathrm{~h}$ reaction time, in line with expectations for this strong XB donor (Table 1, entry, 6). Compounds 11-13 showed no activity (Table 1, entries 7-13), likely due to the lack of chalcogen bonding options and strong $\pi-\pi$ interactions, respectively.

Based upon these findings, all remaining catalyst candidates shown in Figure 2 were tested in the benchmark reaction (Table 2, entries 1-8). Both sulfur- and selenium-based bisbenzimidazolium catalysts 9-10 were similarly active and induced nearly quantitative conversion of compound $1 \mathbf{a}$ after $12 \mathrm{~h}$. This is somewhat unexpected given the higher polarizability of the heavier chalcogen, which should form stronger ChB donors. It is also interesting to note that the more flexible core structure in catalysts $\mathbf{9}^{\text {SMe }}$ and $\mathbf{9}^{\text {SeMe }}$ is slightly superior to more preorganized framework structures such as in catalysts $\mathbf{1 0}$. For the latter, the difference in activity between the syn- and anti-atropisomer is negligible in the observed timeframe. More precisely, catalyst $\mathbf{9}^{\text {SeMe }}$ yielded $95 \%$ of compound 3a, whereas syn-10 $\mathbf{1 0}^{\text {seme }}$ and anti-10 $\mathbf{1 0}^{\text {SeMe }}$ provided $91 \%$ and $90 \%$ of the product, respectively (Table 2, entries 4, 6 and 8). These findings could potentially be explained by the fact that syn-10 $\mathbf{1 0}^{\text {SeMe }}$ may not bind in a clean bidentate fashion to the substrate. Its core structure, it should be stressed, was developed for halogen bond donors interacting with halides. Thus, it seems that the more flexible backbone of $\mathbf{9}^{\mathbf{S e M e}}$ is better able to adapt to the coordination of the target. The corresponding sulfur-based catalysts show the same trend (Table 2, entries 3, 5 and 7).

In contrast, a significant decrease in the conversion of 1a was observed when catalysts $\mathbf{8}^{\text {SMe }}$ and $\mathbf{8}^{\text {SeMe }}$, with the less polarizing imidazolium moieties, were used (Table 2 , entries 1 and 2). After 12 h reaction time, only 21\% of compound 3a were obtained with catalyst $\mathbf{8}^{\text {SeMe }}$ and only $15 \%$ with catalyst $\mathbf{8}^{\text {SMe }}$. Even after $24 \mathrm{~h}$ reaction time, both catalysts yielded only approximately $50 \%$ of compound $3 a$. This 
Table 2 Overview of the Cationic Sulfur- and Selenium-Based Catalysts (Figure 1) in the Reduction of 2-Phenylquinoline (1a)

\begin{tabular}{llll}
\hline Entry & Catalyst & Mol\% $^{\mathrm{a}}$ & ${\text { Yield of } \mathbf{3 a}(\%)^{\mathrm{b}}}^{\mathrm{b}}$ \\
\hline 1 & $\mathbf{8}^{\text {SMe }}$ & 1 & 15 \\
2 & $\mathbf{8}^{\text {SeMe }}$ & 1 & 21 \\
3 & $\mathbf{9}^{\text {SMe }}$ & 1 & 94 \\
4 & $\mathbf{9}^{\text {SeMe }}$ & 1 & 95 \\
5 & syn-10 & 1 & 92 \\
6 & syn-10 & 1 & 91 \\
7 & anti-10 & 1 & 90 \\
8 & anti-10 & 1 & 90 \\
\hline
\end{tabular}

a Catalyst loading with respect to the amount of $\mathbf{1 a}$.

${ }^{b}$ After $12 \mathrm{~h}$ reaction time. Determined via ${ }^{1} \mathrm{H}$ NMR spectroscopy and relative to TES as internal standard. Averaged values of three measurements. A measurement error of $\pm 10 \%$ is assumed.

observation is in accordance with previous results concerning the weak performance of imidazolium-based ChB donors in carbon-chlorine bond activation. ${ }^{27}$

Finally, relative rate constants were determined for selected catalysts (Table 3 and Figure 3; shown for the first $5 \mathrm{~h}$ of reaction time, full kinetic profile is given in the Supporting Information). To this end, the least active reference compound anti-10 $\mathbf{1 0}^{\mathrm{cl}}$ served as standard for comparison $\left(k_{\mathrm{rel}}\right.$ $=1$ ). For the most potent catalysts $\mathbf{9}^{\text {SMe }}$ and $\mathbf{9}^{\text {seMe }}$, relative rate accelerations of about 2000 and 2300 were determined (Table 3, entries 6 and 7). In both cases, the related syn-atropisomers were markedly less active, with rate accelerations being $1.7\left(\mathbf{9}^{\text {SeMe }}\right.$ vs. syn-10 $\left.\mathbf{1 0}^{\text {SeMe }}\right)$ or 1.8 times ( $\mathbf{9}^{\text {SMe }}$ vs. syn-10 ${ }^{\text {SMe }}$ ) higher for the more flexible catalysts (entries 4 and 5). The analogous hydrogen-bond donors syn $/$ anti- $^{-10}{ }^{\mathbf{H}}$ and $\mathbf{9}^{\mathbf{H}}$ showed 5-15 fold less rate acceleration than the best ChB donors (entries 2 and 3 ).

Table 3 Relative Rate Constants for Selected ChB Donors, with Reference Compound anti-10 ${ }^{\mathrm{Cl}}$ as Standard.

\begin{tabular}{llr}
\hline Entry & Catalyst & $k_{\text {rel }}{ }^{\text {a }}$ \\
\hline 1 & anti-10 & 1 \\
2 & syn/anti-10 & 150 \\
3 & $9^{\text {H b }}$ & 450 \\
4 & syn-10 & 1200 \\
5 & syn-10 & 1300 \\
6 & $9^{\text {SeMe }}$ & 2000 \\
7 & $9^{\text {SMe }}$ & 2300 \\
\hline
\end{tabular}

a Normalized rate constant (relative to anti-10
b Inseparable $40: 60$ mixture of syn/anti-10 $\mathbf{0}^{\mathrm{H}}$.

The strong performance of the sulfur-based catalysts may in fact not be entirely unexpected, as there are several examples in the literature in which intramolecular sulfur-

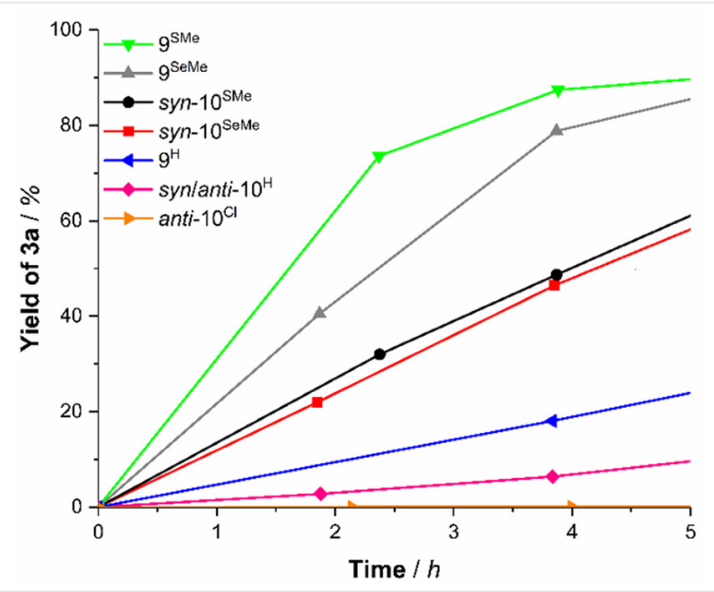

Figure 3 Kinetic profile of the reduction of 2-phenylquinoline (1a) in the presence of selected ChB, HB and XB donors. Kinetic profile for $12 \mathrm{~h}$ reaction time is given in the Supporting Information.

based chalcogen bonds play a major role in the stabilization of transition states of organocatalyzed reactions. ${ }^{37-43}$

In comparison to neutral $\mathrm{ChB}$ donors, which were reported earlier as catalysts for this reaction, the seleniumbased cationic catalysts were approximately twice as active (based on the time needed for full conversion), ${ }^{25}$ whereas the sulfur-based compounds were about 24 times more active, even though $1 \mathrm{~mol} \%$ of catalyst was used compared with the $30 \mathrm{~mol} \%$ of the earlier reports. ${ }^{24}$ This impressively demonstrates the power of charge-assisted chalcogen bonding, particularly for the comparably weakly polarizable sulfur center.

Finally, the most active bisbenzimidazolium based catalysts $\mathbf{9}^{\text {SMe }}$ and $\mathbf{9}^{\text {SeMe }}$ were applied in a small substrate screening involving selected quinolines $\mathbf{1 b}-\mathbf{d}$, which had proven to be very challenging for neutral chalcogen bond donors. ${ }^{24,25}$ First, the background reactivity of the quinolones in the absence of any activating reagent was determined (Table 4, entries 1-3) and was found to be very low. In contrast to neutral $\mathrm{ChB}$ donors, which provided no or very low yields of products $\mathbf{3 b} \mathbf{b}-\mathbf{d}$, the cationic $\mathrm{ChB}$ catalysts induced up to $82 \%$ product formation (Table 4 , entries 4-9).

For both catalysts, the very electron-poor quinoline 3c was reduced most efficiently (Table 4 , entries 5 and 8 ). Selenium-based catalyst $\mathbf{9}^{\text {SeMe }}$ seems less suitable for the reduction of electron-rich quinolines (such as 3d) than its sulfurbased analogue $\mathbf{9}^{\text {sMe }}$ (cf. entries 6 and 9 ). This could be explained by either a stronger catalyst-substrate coordination (which may result in a less favorable product liberation from the catalyst) or by a competing coordination of the catalyst to the electron-rich methoxy substituent of the substrate. $^{25}$

In conclusion, the first application of cationic sulfurand selenium-based chalcogen bond donors in the activation of neutral compounds was presented. Based on a series 
Table 4 Yields for the Reduction of Quinolines $\mathbf{1 b} \mathbf{b}-\mathbf{d}$ in the Presence of Chalcogen Bond Donors 9

\begin{tabular}{|c|c|c|c|}
\hline Entry & Catalyst $^{\mathrm{a}}$ & Product & Yield of $\mathbf{3 b}-\mathbf{d}(\%)^{b}$ \\
\hline 1 & - & $3 b$ & 0 \\
\hline 2 & - & $3 c$ & $6(13)$ \\
\hline 3 & - & $3 d$ & 0 \\
\hline 4 & $9^{\text {SMe }}$ & $3 b$ & $57(62)$ \\
\hline 5 & $9^{\text {sMe }}$ & $3 c$ & $88(>95)$ \\
\hline 6 & $9^{\text {sMe }}$ & $3 d$ & $56(73)$ \\
\hline 7 & $9^{\text {SeMe }}$ & $3 b$ & $50(63)$ \\
\hline 8 & $9^{\text {seMe }}$ & $3 c$ & $92(>95)$ \\
\hline 9 & $9^{\text {seme }}$ & $3 d$ & $38(61)$ \\
\hline
\end{tabular}

a 1 mol\% catalyst was applied with respect to the amount of $\mathbf{1 b}$-d. ${ }^{b}$ After $12 \mathrm{~h}$ reaction time. Yield in brackets after $24 \mathrm{~h}$. Determined via ${ }^{1} \mathrm{H}$ NMR spectroscopy. Averaged values of two measurements. A measurement error of $\pm 10 \%$ is assumed.

of comparison experiments, alternative modes of activation could be ruled out. Overall, rate accelerations of up to 2300 were observed compared with inactive reference compounds. The strong performance of the cationic $\mathrm{ChB}$ donors allowed the activation of very electron-poor or electronrich substrates, which were hitherto difficult to activate.

Two findings in particular were somewhat unexpected: the better performance of catalysts with flexible core structures in comparison to their conformationally locked synatropisomers, and the potency of sulfur-based ChB donors. Given that the latter are easier to synthesize and handle than their selenium-based analogues, it seems that sulfurcontaining Lewis acids could have great potential in chalcogen-bonding-based catalysis. Additional studies to further implement such compounds in noncovalent organocatalysis are under way.

\section{Funding Information}

This project has received funding from the European Research Council (ERC) under the European Union's Horizon 2020 research and innovation programme (638337).

\section{Supporting Information}

Supporting information for this article is available online at https://doi.org/10.1055/s-0039-1690110.

\section{References and Notes}

(1) Doyle, A. G.; Jacobsen, E. N. Chem. Rev. 2007, 107, 5713.

(2) Alemán, J.; Parra, A.; Jiang, H.; Jørgensen, K. A. Chem. Eur. J. 2011, 17, 6890 .

(3) Zhao, Y.; Beuchat, C.; Domoto, Y.; Gajewy, J.; Wilson, A.; Mareda, J.; Sakai, N.; Matile, S. J. Am. Chem. Soc. 2014, 136, 2101.
(4) Schottel, B. L.; Chifotides, H. T.; Dunbar, K. R. Chem. Soc. Rev. 2008, 37, 68.

(5) Bulfield, D.; Huber, S. M. Chem. Eur. J. 2016, 41, 14434.

(6) Cavallo, G.; Metrangolo, P.; Milani, R.; Pilati, T.; Priimagi, A.; Resnati, G.; Terraneo, G. Chem. Rev. 2016, 116, 2478.

(7) Nagorny, P.; Sun, Z. Beilstein J. Org. Chem. 2016, 12, 2834.

(8) Tepper, R.; Schubert, S. U. Angew. Chem. Int. Ed. 2018, 57, 6004.

(9) Vogel, L.; Wonner, P.; Huber, S. M. Angew. Chem. Int. Ed. 2019, $58,1880$.

(10) Lim, J. Y. C.; Beer, P. D. Chemistry 2018, 4, 731.

(11) Gleiter, R.; Haberhauer, G.; Werz, D. B.; Rominger, F.; Bleiholder, C. Chem. Rev. 2018, 118, 2010.

(12) Mahmudov, K. T.; Kopylovich, M. N.; Guedes da Silva, M. F. C.; Pombeiro, A. J. L. Dalton Trans. 2017, 10121.

(13) (a) Murray, J. S.; Lane, P.; Clark, T.; Politzer, P. J. Mol. Model. 2007, 13, 291. (b) Rosenfield, R. E.; Parthasarathy, R.; Dunitz, J. D. J. Am. Chem. Soc. 1977, 99, 4860. (c) Murray, J. S.; Lane, P.; Clark, T.; Politzer, P. J. Mol. Model. 2009, 15, 723. (d) Pearson, R. G. J. Am. Chem. Soc. 1963, 85, 3533. (e) Ramasubbu, N.; Parthasarathy, R.; Murray-Rust, P. J. Am. Chem. Soc. 1986, 108, 4308. (f) Murray-Rust, P.; Motherwell, W. D. S. J. Am. Chem. Soc. 1979, 101, 4374. (g) Politzer, P.; Murray, J. S.; Clark, T. Phys. Chem. Chem. Phys. 2010, 12, 7748. (h) Politzer, P.; Riley, K. E.; Bular, F. A.; Murray, J. S. Comput. Theor. Chem. 2012, 998, 2.

(14) Wang, W.; Ji, B.; Zhang, Y. J. Phys. Chem. A 2009, 113, 8132.

(15) Bleiholder, C.; Gleiter, R.; Werz, D. B.; Köppel, H. Inorg. Chem. 2007, 46, 2249.

(16) (a) Mukherjee, A. J.; Zade, S. S.; Singh, H. B.; Sunoj, R. B. Chem. Rev. 2010, 110, 4357. (b) Werz, D. B.; Gleiter, R.; Rominger, F. J. Am. Chem. Soc. 2002, 124, 10638. (c) Werz, D. B.; Gleiter, R.; Romiger, F. J. Org. Chem. 2002, 67, 4290. (d) Schulte, J. H.; Werz, D. B.; Romiger, F.; Gleiter, R. Org. Biomol. Chem. 2003, 1, 2788. (e) Werz, D. B.; Gleiter, R.; Romiger, F. Organometallics 2003, 22, 843. (f) Gleiter, R.; Werz, D. B.; Rausch, B. J. Chem. Eur. J. 2003, 9, 2676. (g) Bleiholder, C.; Werz, D. B.; Köppel, H.; Gleiter, R. J. Am. Chem. Soc. 2006, 128, 2666.

(17) Iwaoka, M.; Tomoda, S. J. Am. Chem. Soc. 1996, 118, 8077.

(18) Wirth, T. Angew. Chem. Int. Ed. Engl. 1995, 34, 1726.

(19) Garrett, G. E.; Carrera, E. I.; Seferos, D. S.; Taylor, M. S. Chem. Commun. 2016, 52, 9881.

(20) Garrett, G. E.; Gibson, G. L.; Straus, R. N.; Seferos, D. S.; Taylor, M. S. J. Am. Chem. Soc. 2015, 137, 4126.

(21) Lim, J. Y. C.; Marques, I.; Félix, V.; Beer, P. D. Chem. Commun. 2018, 54, 10851.

(22) Lim, J. Y. C.; Marques, I.; Thompson, A. L.; Christensen, K. E.; Félix, V.; Beer, P. D. J. Am. Chem. Soc. 2017, 139, 3122.

(23) Lim, J. Y. C.; Liew, J. Y.; Beer, P. D. Chem. Eur. J. 2018, 24, 14560.

(24) Benz, S.; López-Andarias, J.; Mareda, J.; Sakai, N.; Matile, S. Angew. Chem. Int. Ed. 2017, 56, 812

(25) Benz, S.; Mareda, J.; Besnard, C.; Sakai, N.; Matile, S. Chem. Sci. 2017, 8, 8164.

(26) (a) Wonner, P.; Vogel, L.; Düser, M.; Gomes, L.; Kniep, F.; Mallick, B.; Werz, D. B.; Huber, S. M. Angew. Chem. Int. Ed. 2017, 56,12009 .

(b) General procedure for the synthesis of chalcogeno ureas 11-13: Under an argon atmosphere, the respective bis(benz)imidazolium compound (1 equiv) was added to a Schlenk flask and dissolved in anhydrous methanol $(0.17 \mathrm{M}$; dried for $24 \mathrm{~h}$ over molecular sieve). To the solution, elemental selenium powder or sulfur ( 2.5 equiv) and cesium carbonate ( 2.5 equiv) were added. The mixture was heated at reflux for $24 \mathrm{~h}$ and finally filtered (hot solution) over a short plug of silica and rinsed with $\mathrm{CH}_{2} \mathrm{Cl}_{2}$. After the solvent was removed, the 
crude solid was purified by column chromatography (solvents noted for specific compounds). All spectroscopic data are given in the Supporting Information.

(c) General methylation procedure for the synthesis of compounds 8-10: Under an argon atmosphere, the respective chalcogenourea compound (1 equiv) was dissolved in anhydrous $\mathrm{CH}_{2} \mathrm{Cl}_{2}$. Then methyl trifluoromethanesulfonate (2.5 equiv) was slowly added at $0{ }^{\circ} \mathrm{C}$ and the reaction mixture was stirred for $24 \mathrm{~h}$ at room temperature. After the solvent was removed under reduced pressure, the crude residual was diluted in a little acetonitrile and was precipitated by addition of diethyl ether. The solid was filtered off, washed with diethyl ether and pentane and dried under high vacuum. Alternatively, the solvent was removed, and the residue was washed under sonification several times with ether and pentane. Finally, the respective methylated chalcogenated compound was obtained as colorless solid. All spectroscopic data are given in the Supporting Information.

(d) Spectroscopic data for selected compounds $9^{\text {SeMe }}, 9^{\text {sMe }}$ and syn-10 ${ }^{\text {SMe. }}$

Compound 9 $^{\text {seme }}$ : Yield: $294 \mathrm{mg}$ (74\%); solid; ${ }^{1} \mathrm{H}$ NMR (300 MHz, $\left.\mathrm{CDCl}_{3}\right): \delta=8.50(\mathrm{~s}, 1 \mathrm{H}), 8.17(\mathrm{dd}, J=7.10,1.80 \mathrm{~Hz}, 2 \mathrm{H}), 8.08$ (dd, $J=9.00,6.80 \mathrm{~Hz}, 1 \mathrm{H}), 7.69(\mathrm{~m}, 6 \mathrm{H}), 7.43$ (dd, $J=7.50$, $0.80 \mathrm{~Hz}, 2 \mathrm{H}), 4.67$ (d, $J=8.00 \mathrm{~Hz}, 4 \mathrm{H}), 2.41$ (s, $6 \mathrm{H}), 2.01$ (q, $J=$ $7.70 \mathrm{~Hz}, 4 \mathrm{H}), 1.31$ (m, $20 \mathrm{H}), 0.87$ (m, $6 \mathrm{H}) .{ }^{13} \mathrm{C}$ NMR (101 MHz, $\left.\mathrm{CD}_{3} \mathrm{CN}\right): \delta=147.29,136.10,135.34,133.76,133.48,131.77$, 128.22, 128.59, 128.39, 122.09 (d, $J=321.0 \mathrm{~Hz}), 114.49,114.07$, 49.88, 32.48, 30.24, 28.79 (d, $J=4.50 \mathrm{~Hz}$ ), 27.34, 23.34, 14.38, 11.51. ${ }^{19} \mathrm{~F}$ NMR $\left(235 \mathrm{MHz}, \mathrm{CD}_{3} \mathrm{CN}\right): \delta=-78.53(\mathrm{~s}, 6 \mathrm{~F})$. ATR-IR: $3073(\mathrm{w}), 2928$ (w), 2857 (w), 1738 (w), 1603 (w), 1501 (m), 1477 (m), 1429 (m), 1358 (w), 1250 (vs), 1223 (s), 1148 (s), 1086 (w), 1028 (vs), 926 (w), 831 (w), 800 (w), 752 (s), 698 (w), 635 (vs), 571 (m), 515 (s), 432 (w) $\mathrm{cm}^{-1}$. ESI-MS (+): $\mathrm{m} / \mathrm{z}$ [M-OTf] ${ }^{+}$calcd. 873.21; found: 872.87; ESI-MS (-): $m / z$ [OTf] ${ }^{-}$ calcd. 148.95; found 148.80. Anal. calcd. for CHNS: C, 51.82; H, 5.65; N, 6.04; S, 13.83; found: C, 51.79; H, 5.42; N, 5.77; S, 13.72. Compound 9sMe: Yield: $620 \mathrm{mg}$ (79\%); solid; ${ }^{1} \mathrm{H}$ NMR (300 MHz, $\left.\mathrm{CDCl}_{3}\right): \delta=8.50(\mathrm{~s}, 1 \mathrm{H}), 8.15(\mathrm{~m}, 3 \mathrm{H}), 7.68(\mathrm{sd}, J=8.4,1.3 \mathrm{~Hz}$, $6 \mathrm{H}), 7.43(\mathrm{~d}, J=7.7 \mathrm{~Hz}, 2 \mathrm{H}), 4.64(\mathrm{~d}, J=7.7 \mathrm{~Hz}, 4 \mathrm{H}), 2.51(\mathrm{~s}$, $6 \mathrm{H}), 2.02(\mathrm{p}, J=7.7 \mathrm{~Hz}, 4 \mathrm{H}), 1.38(\mathrm{~m}, 20 \mathrm{H}), 0.87(\mathrm{~m}, 6 \mathrm{H}) .{ }^{13} \mathrm{C}$ NMR $\left(101 \mathrm{MHz}, \mathrm{CD}_{3} \mathrm{CN}\right): \delta=151.20,135.35,134.66,134.08$, 132.97, 131.67, 129.18, 128.83, 127.88, 114.53, 113.93, 48.76, 32.48, 30.11, 29.79 (d, $J=5.40 \mathrm{~Hz}$ ), 27.35, 23.40, 18.51, 14.37 . ${ }^{19} \mathrm{~F}$ NMR $\left(235 \mathrm{MHz}, \mathrm{CD}_{3} \mathrm{CN}\right)$ : $\delta=-79.28$ (s, $\left.6 \mathrm{~F}\right)$. ATR-IR: 3073 (w), 2928 (w), 2857 (w), 1738 (w), 1603 (w), 1501 (w), 1477 (w), 1462 (w), 1431 (w), 1364 (w), 1254 (s), 1223 (m), 1150 (m), 1088 (w), 1028 (vs), 847 (w), 802 (w), 752 (m), 698 (w), 634 (vs), $571(\mathrm{w}), 515(\mathrm{~m}) \mathrm{cm}^{-1}$. ESI-MS (+): $\mathrm{m} / \mathrm{z}\left[\mathrm{M}+\mathrm{OTf}^{+}\right.$ calcd. 777.32; found: 777.51; ESI-MS (-): $m / z$ [OTf] $]^{-}$calcd. 148.95; found: 149.00. Anal. calcd. CHNS: C, 51.82; H, 5.65; N, 6.04; S, 13.83; found: C, 51.79; H, 5.42; N, 5.77; S, 13.72.

Compound syn-10 ${ }^{\text {SMe }}$ : Yield: $323 \mathrm{mg}$ (87\%); solid; ${ }^{1} \mathrm{H}$ NMR (300 $\left.\mathrm{MHz}, \mathrm{CD}_{3} \mathrm{CN}\right): \delta=8.40(\mathrm{t}, J=8.1 \mathrm{~Hz}, 1 \mathrm{H}), 8.24(\mathrm{~d}, J=8.1 \mathrm{~Hz}, 2 \mathrm{H})$, $8.04(\mathrm{dd}, J=7.3,2.0 \mathrm{~Hz}, 2 \mathrm{H}), 7.81(\mathrm{dtd}, J=13.0,7.3,1.4 \mathrm{~Hz}, 4 \mathrm{H})$, $7.67(\mathrm{~d}, J=7.7 \mathrm{~Hz}, 2 \mathrm{H}), 4.71(\mathrm{td}, J=7.4,1.9 \mathrm{~Hz}, 4 \mathrm{H}), 2.51(\mathrm{~s}$, $6 \mathrm{H}), 2.03(\mathrm{~m}, 4 \mathrm{H}), 1.28(\mathrm{~m}, 20 \mathrm{H}), 0.87(\mathrm{~m}, 6 \mathrm{H}) .{ }^{13} \mathrm{C}$ NMR $(101$ $\left.\mathrm{MHz}, \mathrm{CD}_{3} \mathrm{CN}\right): \delta=151.83,138.65,136.31,135.17,133.42(\mathrm{~d}, J=$ $1.60 \mathrm{~Hz}), 132.81,129.84,129.26,127.14(\mathrm{q}, J=31.0 \mathrm{~Hz}), 122.12$ $(\mathrm{d}, J=321.5 \mathrm{~Hz}), 114.93,114.37,49.30,32.36,29.88,29.68$ (d, $J=8.80 \mathrm{~Hz}), 27.09,23.30,18.89,14.34 .{ }^{19} \mathrm{~F}$ NMR $(235 \mathrm{MHz}$, $\left.\mathrm{CD}_{3} \mathrm{CN}\right): \delta=-56.73(\mathrm{~s}, 3 \mathrm{~F}),-79.32(\mathrm{~s}, 6 \mathrm{~F})$. ATR-IR: $2927(\mathrm{w})$, 2857 (w), 1547 (w), 1501 (w), $1477(w), 1433(w), 1364(w)$, 1256 (vs), 1223 (m), 1175 (m), 1140 (m), 1028 (s), 984 (w), $858(\mathrm{w}), 752$ (m), 687 (w), 635 (s), 573 (m), 517 (w), 434 (w) $\mathrm{cm}^{-1}$. ESI-MS (+): $\mathrm{m} / z$ [M+OTf $]^{+}$calcd. 845.31; found: 845.27; ESI-MS (-): $m / z$ [OTf] ${ }^{-}$calcd. 148.95; found: 148.66 . Anal. calcd. CHNS: C, 49.49; H, 5.17; N, 5.63; S, 12.89; found: C, 48.55; H, 4.94; N, 5.53; S, 12.37.

(27) Wonner, P.; Vogel, L.; Kniep, F.; Huber, S. M. Chem. Eur. J. 2017, 23, 16972.

(28) Benz, S.; Besnard, C.; Matile, S. Helv. Chim. Acta 2018, 101, e1800075.

(29) Sebastian, B.; Poblador-Bahamonde, A. I.; Nicolas, L. D.; Stefan, M. Angew. Chem. Int. Ed. 2018, 57, 5408.

(30) Bolm, C.; Bruckmann, A.; Pena, M. Synlett 2008, 900.

(31) Jungbauer, S. H.; Schindler, S.; Kniep, F.; Walter, S. M.; Rout, L.; Huber, S. M. Synlett 2013, 24, 2624.

(32) Togo, H.; Iida, S. Synlett 2006, 2159.

(33) General Procedure for the Reduction of 1a:

In a dry NMR tube, freshly prepared stock solutions of the respective catalyst $(100 \mu \mathrm{L}, 2.5 \mathrm{~mm})$, the quinoline derivative $(100 \mu \mathrm{L}, 250 \mathrm{~mm})$ and the Hantzsch ester $(400 \mu \mathrm{L}, 150 \mathrm{mM})$ were added, sealed and shaken for $1 \mathrm{~min}$. Afterwards, a series of ${ }^{1} \mathrm{H}$ NMR measurements were performed with a total duration of $12 \mathrm{~h}$ (for selected derivatives $24 \mathrm{~h}$ ). As internal standard TES ( 0.125 equiv) was added to the quinoline stock solution.

(34) The syn-12BIm-Cl atropisomer decomposed during its synthesis.

(35) Jungbauer, S. H.; Huber, S. M. J. Am. Chem. Soc. 2015, 137, 12210.

(36) Gliese, J. P.; Jungbauer, S. H.; Huber, S. M. Chem. Commun. 2017, $53,12052$.

(37) Srivastava, K.; Chakraborty, T.; Singh, H. B.; Butcher, R. J. Dalton Trans. 2011, 4489.

(38) Srivastava, K.; Shah, P.; Singh, H. B.; Butcher, R. J. Organometallics 2011, 30, 534.

(39) Nagao, T.; Hirata, S.; Goto, S.; Sano, S.; Kakehi, A.; Iizuka, K.; Shiro, M. J. Am. Chem. Soc. 1998, 12, 3104.

(40) Franchetti, P.; Cappellacci, L.; Grifantini, M.; Barzi, A.; Nocentini, G.; Yang, H.; O'Connor, A.; Jayaram, H. N.; Carrell, C.; Goldstein, B. M. J. Med. Chem. 1995, 38, 3829.

(41) Birman, V. B.; Li, X. Org. Lett. 2008, 10, 1115.

(42) Leverett, C. A.; Vikram, V. C.; Purohit, C.; Romo, D. Angew. Chem. Int. Ed. 2010, 49, 9479.

(43) Robinson, E. R. T.; Fallan, C.; Simal, C.; Slawin, A. M. Z.; Smith, A. D. J. Am. Chem. Soc. 2013, 4, 2193. 